\title{
Evaluation of cloud base height measurements from Ceilometer CL31 and MODIS satellite over Ahmedabad, India
}

\author{
Som Sharma ${ }^{1}$, Rajesh Vaishnav ${ }^{1}$, Munn V. Shukla ${ }^{2}$, Prashant Kumar ${ }^{2}$, Prateek Kumar ${ }^{2}$, Pradeep K. Thapliyal ${ }^{2}$, \\ Shyam Lal ${ }^{1}$, and Yashwant B. Acharya ${ }^{1}$ \\ ${ }^{1}$ Physical Research Laboratory, Ahmedabad, India \\ ${ }^{2}$ Space Applications Centre, ISRO, Ahmedabad, India \\ Correspondence to: Som Sharma (somkumar@prl.res.in)
}

Received: 2 October 2015 - Published in Atmos. Meas. Tech. Discuss.: 11 November 2015

Revised: 4 February 2016 - Accepted: 4 February 2016 - Published: 29 February 2016

\begin{abstract}
Clouds play a tangible role in the Earth's atmosphere and in particular, the cloud base height $(\mathrm{CBH})$, which is linked to cloud type, is one of the most important characteristics to describe the influence of clouds on the environment. In the present study, CBH observations from Ceilometer CL31 were extensively studied during May 2013 to January 2015 over Ahmedabad $\left(23.03^{\circ} \mathrm{N}, 72.54^{\circ} \mathrm{E}\right)$, India. A detailed comparison has been performed with the use of ground-based CBH measurements from Ceilometer CL31 and $\mathrm{CBH}$ retrieved from MODIS (Moderate Resolution Imaging Spectroradiometer) onboard Aqua and Terra satellite. CBH retrieved from MODIS is $\sim 1.955$ and $\sim 1.093 \mathrm{~km}$ on 25 July 2014 and 1 January 2015 respectively, which matches well with ceilometer-measured $\mathrm{CBH}(\sim 1.92$ and $\sim 1.097 \mathrm{~km}$ ). Some interesting features of cloud dynamics viz. strong downdraft and updraft have been observed over Ahmedabad which revealed different cloud characteristics during monsoon and post-monsoon periods. $\mathrm{CBH}$ shows seasonal variation during the Indian summer monsoon and postmonsoon period. Results indicate that the ceilometer is an excellent instrument to precisely detect low- and mid-level clouds, and the MODIS satellite provides accurate retrieval of high-level clouds over this region. The $\mathrm{CBH}$ algorithm used for the MODIS satellite is also able to capture the lowlevel clouds.
\end{abstract}

\section{Introduction}

Clouds, visible masses of tiny water droplets or frozen ice crystals, are one of the most crucial parameters for weather and climate prediction (Bauer et al., 2011; Errico et al., 2007; Shah et al., 2010). Kiehl and Trenberth (1997) showed the importance of clouds on the global energy budget. Accurate information of cloud cover is essential for better understating of the climate system (Fontana et al., 2013). Randall et al. (1984) observed that a $4 \%$ increase in the cloud cover with stratocumulus can compensate the global warming due to $\mathrm{CO}_{2}$ doubling. The types of low-level clouds and their development are governed by meteorological conditions, especially in the atmospheric boundary layer, such as vertical stability (Norris, 1998). Koren et al. (2010) discussed that aerosols affect clouds, which contributes to climate change. Andrejczuk et al. (2014) found that cloud albedo may increase as a result of the seeding, if enough aerosols are delivered into the cloud. Kokhanovsky et al. (2007) discussed that the global cloud top height (CTH) is near to $6000 \mathrm{~m}$. Li and Min (2010) showed the impact of mineral dust on tropical clouds which is dependable on rain type. Varikoden et al. (2011) studied cloud base height (CBH) over Thiruvananthapuram $\left(8.4^{\circ} \mathrm{N}, 76.9^{\circ} \mathrm{E}\right)$, India, during different seasons and found diurnal and seasonal variations except rainy days. Zhang et al. (2010) deployed AMF (ARM Mobile Facility) for radiosondes in Shouxian, China, and showed that the diurnal variation in upper-level clouds thickness is larger than that of low-level clouds over this region.

Space-based instruments are widely used to detect clouds globally at high spatial and temporal resolution. Various scientific studies have been performed to retrieve informa- 
tion on clouds, which needs further evaluation with ground observations. At nighttime, $\mathrm{CBH}$ can be retrieved accurately using Visible Infrared Imaging Radiometer Suite algorithms (Hutchison et al., 2006). Meerkötter and Zinner (2007) used an adiabatic algorithm to find CBH from satellite data for convective clouds. Weisz (2007) suggested various algorithms and methods to measure cloud height from space-borne instruments. The ability to determine the cloud top/bottom height is still limited due to the nature of infrared-based passive measurements from satellites (Kim et al., 2011). Bhat and Kumar (2015) used precipitation radar measurement to detect vertical structure of cumulonimbus and convective clouds over the south Asian region. Gu et al. (2011) used the Scale Invariant Feature Transform algorithm to detect clouds from the MODIS (Moderate Resolution Imaging Spectroradiometer) satellite without manual interference.

Lidars have been widely used for both atmospheric boundary-layer structure and cloud-base detection (Mariucci et al., 2007; Albrecht et al., 1990). Liu et al. (2015) used two ceilometers (CL31, CL51) and a whole-sky infrared cloud-measuring system and found significant differences in $\mathrm{CBH}$ due to the retrieval algorithm or measurement principle. Cloud-Aerosol Lidar and Pathfinder Satellite Observations are used to understand the global clouds distribution, cloud statics, and the effect of clouds on the radiation budget (Rasmussen et al., 2002; Wu et al., 2011; Winker et al., 2003). Pal et al. (1992) demonstrated an algorithm to retrieve CTH and $\mathrm{CBH}$ from Nd YAG (neodymium-doped yttrium aluminium garnet) lidar. Duynkerke and Teixeira (2001) determined cloud cover with stratocumulus using observations obtained from the Regional Experiment of International Satellite Cloud Climatology Project. Clothiaux et al. (2000) used multiple active remote sensors like the Belfort or Vaisala Ceilometer and a micro-pulse lidar to find $\mathrm{CBH}$.

Kotarba (2009) evaluated MODIS-derived cloud amount data with visual surface observations over the Poland region. Forsythe et al. (2000) compared cloud information retrieved from GOES- 8 geostationary satellite with surface observation. Stefan et al. (2014) used both ceilometer and satellite data to detect clouds and found that low-level clouds are better captured by the ceilometer, and for high-level clouds, satellites provide better information. Albrecht et al. (1990) used a sodar, ceilometer, and microwave radiometer all together to estimate cloud thickness. Kassianov et al. (2005) estimated CBH from hemispherical surface observations and validated these against micro-pulse lidar (MPL) observations.

Recently, Physical Research Laboratory (PRL) installed Ceilometer CL31 over Ahmedabad, India. The objective of this study is to evaluate the performance of satellitederived cloud features with these ground-based cloud measurements. Detailed investigations of cloud base retrieved from the MODIS satellite are compared with ceilometer measurements during the years 2013 to 2015 . Brief de-
Table 1. Technical specification of Ceilometer CL31.

\begin{tabular}{ll}
\hline Property & Description/value \\
\hline Laser source & Indium gallium arsenide (InGaAs) diode laser \\
\hline Center wavelength & $910 \pm 10 \mathrm{~nm}$ at $25^{\circ} \mathrm{C}\left(77^{\circ} \mathrm{F}\right)$ \\
Operating mode & Pulsed \\
Energy & $1.2 \mu \mathrm{Ws} \pm 20 \%$ (factory adjustment) \\
Width, 50\% & $110 \mathrm{~ns} \mathrm{typical}$ \\
Repetition rate & $10.0 \mathrm{kHz}$ \\
Average power & $12.0 \mathrm{~mW}$ \\
Max irradiance & $760 \mathrm{~W} \mathrm{~cm}{ }^{-2}$ measured with $7 \mathrm{~mm}$ aperture \\
Laser classification & Classified as class $1 \mathrm{M}$ laser device \\
Beam divergence & $\pm 0.4 \mathrm{mrad} \times \pm 0.7$ mrad \\
Receiver detector & Silicon avalanche photodiode \\
\hline
\end{tabular}

tails about ceilometer observations and MODIS data are discussed in Sect. 2. The methodology and results are discussed in Sects. 3 and 4 respectively. Conclusions of the paper are given in Sect. 5.

\section{Data used}

\subsection{Ground observations by the ceilometer}

The ceilometer lidar set up at PRL, Ahmedabad $\left(23.03^{\circ} \mathrm{N}\right.$, $72.54^{\circ} \mathrm{E} ; 55 \mathrm{~m}$ a.m.s.l.; Fig. 1), consists of a vertically pointing laser and a receiver at the same location. Ceilometer CL31 employs pulsed diode laser InGaAs (indium gallium arsenide) lidar technology. The transmitter is an InGaAs pulsed laser diode, operating at a wavelength of $910 \mathrm{~nm}$ $( \pm 10 \mathrm{~nm})$, typically with a peak power of $11 \mathrm{~W}$. The receiving unit is a silicon avalanche photodiode with an interference filter with a center wavelength of $915 \mathrm{~nm}$ and a surface diameter of $0.5 \mathrm{~mm}$. The receiver bandwidth is $3 \mathrm{MHz}$ and $80 \%$ of transmissivity at $913 \mathrm{~nm}$. The focal length of the optical system is $300 \mathrm{~mm}$ with a lens diameter of $96 \mathrm{~mm}$. The model CL31 has the maximum reportable cloud base detection range of $7500 \mathrm{~m}$ above the surface, with the reporting interval of a minimum $2 \mathrm{~s}$ to a maximum $120 \mathrm{~s}$. It can be used in the temperature range of -40 to $+60^{\circ} \mathrm{C}$. The technical specifications of the system are provided in Table 1 . The single lens eye-safe lidar ceilometer reported $\mathrm{CBH}$ at three layers and vertical visibility at lower altitudes regularly. To obtain the height of the cloud base, a laser pulse is sent through the atmosphere. This light pulse is scattered by aerosol particles. A component of this scattered light is received back by the lidar receiver. The received backscattered profile is used to detect the CBH. CL View is an interface software which is a graphical presentation program for cloud height and backscatter profile information. CL view software is used here for data handling and visualization purposes. 
(a) Location of PRL in India

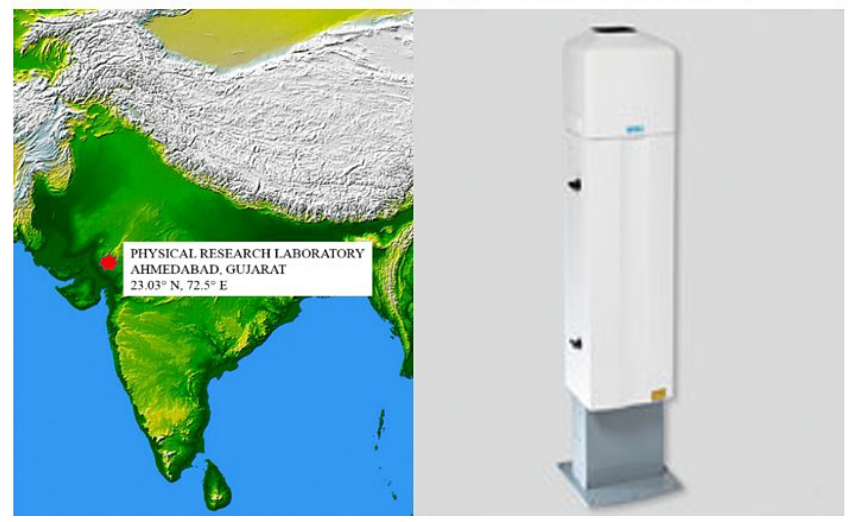

Figure 1. (a) Location of Ahmedabad $\left(23.03^{\circ} \mathrm{N}, 72.54^{\circ} \mathrm{E}\right.$; $55 \mathrm{~m}$ a.m.s.1.), where Ceilometer CL31 is installed, and (b) a photograph of the Vaisala Ceilometer.

\subsection{MODIS-retrieved clouds}

The MODIS is a scientific instrument launched by NASA (National Aeronautics and Space Administration) into the Earth's orbit on board two satellites: Terra, in the year 1999, and Aqua, in the year 2002. It uses 36 spectral bands between wavelengths of 0.41 and $14.2 \mu \mathrm{m}$ (Xiong et al., 2004) and scans a cross-track swath of $2330 \mathrm{~km}$. These bands are divided into four separate focal plane assemblies viz. visible, near-infrared, shortwave infrared, mid-wave infrared, and long-wave infrared. MODIS provides measurements of large-scale global dynamics, including cloud cover, radiation budget, and the processes occurring in the lower atmosphere at $5 \mathrm{~km}$ spatial resolution. The cloud detection algorithm is mainly based on the multispectral analysis of clouds. Reflectance and radiation of clouds are different from the earth's surface in visible and infrared band spectra. The following five bands viz. $\mathrm{CH} 1(0.620-0.670 \mu \mathrm{m}), \mathrm{CH} 2$ $(0.841-0.876 \mu \mathrm{m}), \mathrm{CH} 26(1.360-1.390 \mu \mathrm{m}), \mathrm{CH} 29$ (8.400$8.700 \mu \mathrm{m})$, and $\mathrm{CH} 31(10.780-11.280 \mu \mathrm{m})$ in the near infrared/visible and thermal infrared are used for the cloud spectrum (Gu et al., 2011).

\section{Methodology}

The present study focuses on the most important features of temporal variability of cloudiness over Ahmedabad during May 2013 to January 2015, using cloud data retrieved from the MODIS satellite, in conjunction with cloud observations by the ceilometer. The location map of the Ahmedabad region and a photograph of the Ceilometer CL31 are shown in Fig. 1. The ceilometer data set contains three consecutive heights of multilayer clouds and backscatter coefficients (Martucci et al., 2007, 2010). The MODIS satellite products MOD06_L2 (Hirsch et al., 2011) contain the data from the
Terra satellite, and the "MYD06_L2" files contain data from the Aqua satellite platform that are used in this study. Only the daytime passes of the MODIS satellite over the Ahmedabad region are used in this study. For comparison purposes, MODIS satellite data are used directly, if data lie within a $0.1^{\circ}$ radius of the in situ location. Ceilometer data have very high temporal frequency; because of this suitability, ceilometer data that lie near the MODIS pass are used for comparison purposes.

\section{CBH detection algorithm}

For water clouds, $\mathrm{CBH}$ is measured using $\mathrm{CTH}$ and cloud geometrical thickness (CGT; Meerkötter and Bugliaro, 2009). CGT is derived from two parameters, liquid water path (LWP) which is obtained from the cloud optical thickness $(t)$ and cloud effective radius (reff; $\mathrm{g} \mathrm{m}^{-2}$ ), and liquid water content (LWC), where LWC is the integration of cloud size distribution over droplet size and has units of $\mathrm{g} \mathrm{m}^{-3}$ (Hutchison, 2002). The value of LWC varies according to the types of cloud.

$\mathrm{CBH}=\mathrm{CTH}-\mathrm{CGT}$,

where

$\mathrm{CGT}=\frac{\mathrm{LWP}}{\mathrm{LWC}}$,

$\mathrm{LWP}=\frac{2 \times t \times \mathrm{reff}}{3}$.

Here, $t$ is cloud optical depth and reff is the cloud droplet effective radius.

The value of LWC varies between about 0.03 and $0.45 \mathrm{~g} \mathrm{~m}^{-3}$ (Hess et al., 1998; Rosenfeld and Lensky, 1998). This algorithm of $\mathrm{CBH}$ is restricted to daytime data only, because the cloud optical thickness and effective radius are available only in sunlit regions of the Earth (Hutchison, 2002).

\section{Results and discussions}

This study investigates cloud analysis over the Ahmedabad region using ceilometer measurements and MODIS satellite-retrieved cloud parameters. The scanning frequency of MODIS satellite above the Ahmedabad region is twice per day, whereas the ceilometer provides $\sim 100 \%$ monthly coverage at high temporal resolution. The number of observations was 379 days during the years 2013 to 2015 . Figure 2 shows the sample vertical backscattering profile for different days and times. In Fig. 2a, the maximum backscattering is seen at $7.22 \mathrm{~km}$ on 6 June 2013 at 02:00:02 IST which shows the availability of high-level clouds. Figure $2 \mathrm{~b}$ shows the detection of multilayer clouds in which low-level and mid-level clouds appear together. The peak backscattering is at $4 \mathrm{~km}$, which provides us information about mid-level clouds, as 


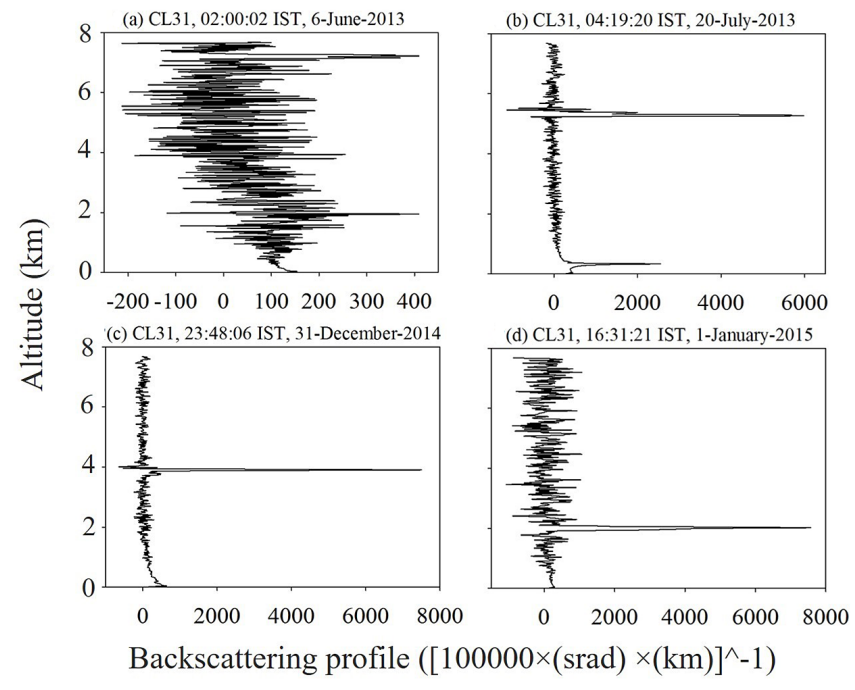

Figure 2. Vertical profile of backscatter data for different days (a) 6 June 2013 at 02:00:02 IST, (b) 20 July 2013 at 04:19:20 IST, (c) 31 December 2014 at 23:48:06 IST, and (d) 1 January 2015 at 16:32:21 IST from Ceilometer CL31 over Ahmedabad, India.

found in Fig. 2c. In Fig. 2d, the maximum backscattering is seen at $2 \mathrm{~km}$, which gives information on low-level clouds.

Figure 3 a shows the detection of multilayer clouds using the ceilometer instrument. In this figure, both the intensity and back scattering profile and three layers of clouds with a corresponding height of $0.384,1.8$, and $2 \mathrm{~km}$ are seen at 15:29:50 IST. Figure $3 \mathrm{~b}$ shows the detection of multilayer clouds for 2 August 2014. The strong updraft and downdraft can be seen in the lower panel of Fig. 3b. Continuous updraft and downdraft can be found from $1 \mathrm{~km}$ height to $3 \mathrm{~km}$ height till 18:00 IST. Strong downdraft was seen from 13:44 to $13: 51$ IST with the velocity of $2.1 \mathrm{~m} \mathrm{~s}^{-1}$, and strong updraft was observed from 16:36 to 16:51 IST with the velocity of $1.8 \mathrm{~m} \mathrm{~s}^{-1}$. On 22 July 2013 from 03:00 to 04:00 IST, the ceilometer detected multilayer clouds, which move with almost constant velocity (figure not shown). At 03:21 IST, the corresponding backscatter profile in which maximum backscattering seen at $320 \mathrm{~m}$ and $3.520 \mathrm{~km}$ provides information about low-level and mid-level clouds. Similarly, on 25 July 2015 (01:00 to 02:00 IST) and 1 August 2015 (16:00 to 18:00 IST), low-level clouds appear at 1 to $0.860 \mathrm{~km}$ respectively and a second layer of clouds $(\mathrm{CBH} 2)$ is seen from the backscattering at 3.5 to $3.13 \mathrm{~km}$ respectively. These investigations from continuous $\mathrm{CBH}$ measurements at high temporal resolution (every $2 \mathrm{~s}$ ) show that the ceilometer is able to capture the multilayer clouds, which may be an important input for various meteorological applications. With the use of very high temporal resolution $\mathrm{CBH}$ observations from ceilometers, $\mathrm{CBH}$ shows an updraft over the Ahmedabad region on 1 January 2015 between 14:00 to 16:00 IST. The ceilometer also captured the two-layer low clouds at 0.201 and $1.316 \mathrm{~km}$ on 25 July 2013, and corre- (a)
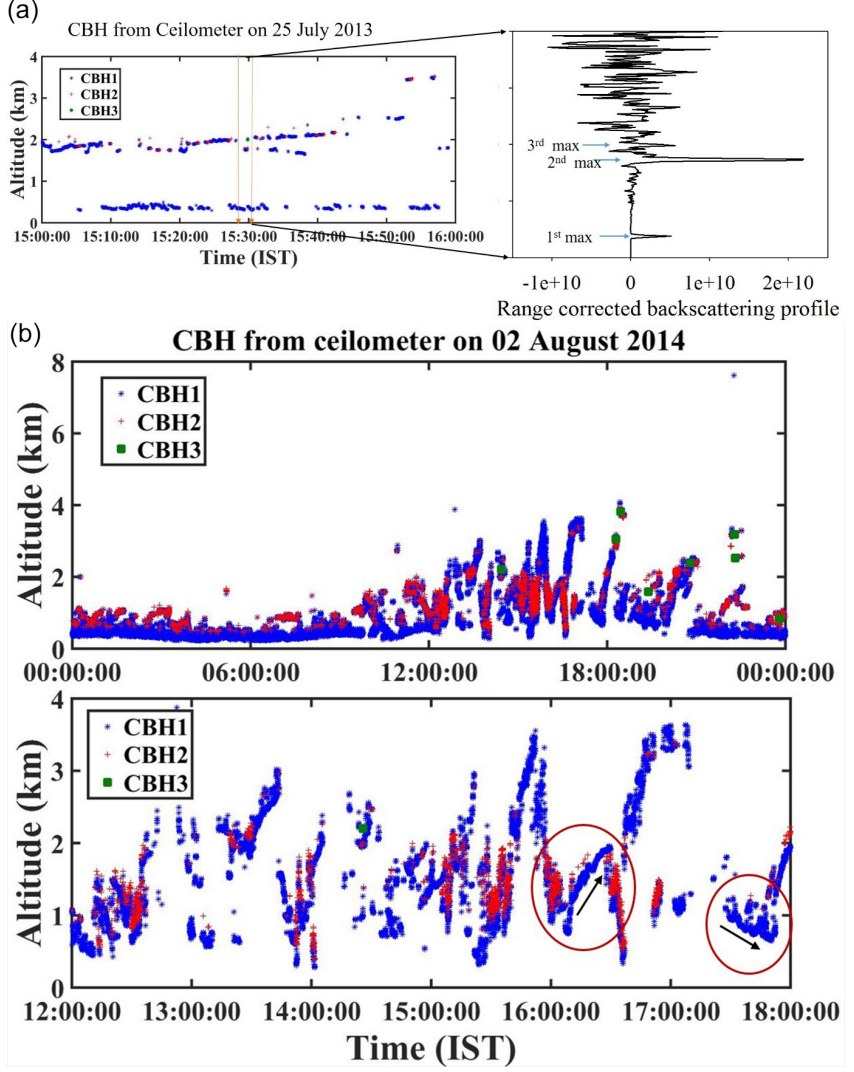

Figure 3. (a) Cloud intensity with range-corrected backscattering profile for multilayer cloud detection on 25 July 2013 at 15:29:50 IST. (b) Evolution of three layers of CBH measured by the ceilometer on 2 August 2014 (upper panel) along with strong updraft and downdraft (lower panel) for the same day.

sponding backscatter values show peak at the same heights. The ceilometers detect three layers of clouds on 30 October 2014 at 22:40 IST, and this shows the capability of the instrument to measure multilayer clouds. From these experiences to detect multilayer clouds at different altitudes, we can state that the ceilometer provides better information on the low- and mid-level clouds. Recently, Stefan et al. (2014) used a similar ground-based instrument to study cloud cover over Măgurele, Romania, and compared these with the MODIS satellite. These results infer that ceilometer-observed lowand mid-level clouds are very precise, and high-level clouds can be accurately detected by the satellite. The comparison has been made between the ceilometer and MODIS satellite in Fig. 4, which shows the cloud cover over the Ahmedabad region for 3 different days.

\subsection{Comparison of cloud heights from the ceilometer and MODIS}

In this section, the $\mathrm{CTH}$ retrieved from the passive remote sensor viz. MODIS and active remote sensor viz. the ceilometer (Naud et al., 2003) are compared for cloud detec- 
Table 2. Comparison between ceilometer and MODIS satellite-measured clouds.

\begin{tabular}{llrrr}
\hline \multirow{2}{*}{ Serial no. } & Date/time (IST) & Ceilometer data & \multicolumn{2}{c}{ MODIS data } \\
\cline { 3 - 5 } & & CBH1 $(\mathrm{km})$ & $\mathrm{CTH}(\mathrm{km})$ & $\mathrm{CBH}(\mathrm{km})$ \\
\hline 1 & 1 Jan 2015 14:25 & 1.097 & 2.000 & 1.093 \\
2 & 20 Jul 2014 20:40 & 1.079 & 0.250 & NA \\
3 & 21 Jul 2014 02:15 & 1.911 & NA & NA \\
4 & 25 Jul 2014 13:45 & 0.685 & 3.100 & NA \\
5 & 26 Jul 2014 02:35 & 2.487 & 3.400 & NA \\
6 & 25 Jul 2014 14:25 & 1.920 & 4.250 & 1.955 \\
7 & 30 Jul 2014 11:35 & 0.440 & 10.900 & NA \\
8 & 5 Sep 2014 11:55 & 0.630 & 4.250 & NA \\
9 & 15 Sep 2014 10:55 & 1.680 & 1.250 & NA \\
10 & 20 Jul 2013 14:40 & 0.786 & 11.250 & NA \\
11 & 21 Jul 2013 02:50 & 7.142 & 13.700 & NA \\
12 & 21 Jul 2013 13:45 & 0.896 & 0.750 & NA \\
13 & 22 Jul 2013 01:45 & 0.429 & 14.100 & NA \\
\hline
\end{tabular}

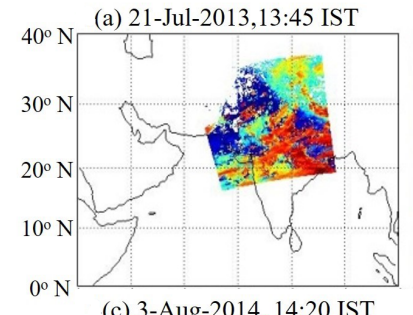

(b) 20-Jul-2014, 14:10 IST

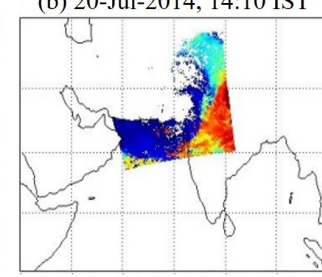

(d) 1-Jan-2015, 02:35 IST
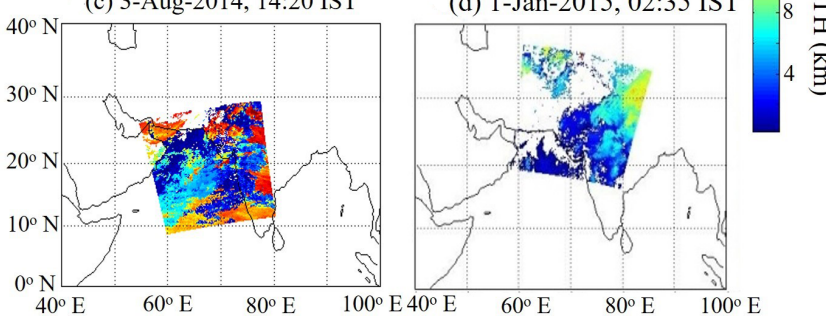

Figure 4. MODIS satellite-retrieved cloud top height for (a) 21 July 2013, (b) 20 July 2014, (c), 3 August 2014, and (d) 1 January 2015 over Ahmedabad, India.

tion (Fig. 5). In the last section, for comparing the accuracy of the ceilometer retrievals, the CBHs derived from the active remote sensor ceilometer are presented. The ceilometer has confirmed its ability to operate throughout the year, taking continuous measurements of the lowest $\mathrm{CBH}$ as found by Costa-Surós et al. (2013). The cloud detections from MODIS and the ceilometer are compared to show the difference between the passive remote sensor and the active remote sensor. The ceilometer can detect three cloud layers simultaneously. As found in Table 2, the different measurements are used for the comparison between the satellite and the ceilometer. Figure 5a shows that on 20 July 2013 between 14:00 to $15: 00$ IST, the CBH is $1 \mathrm{~km}$. At 14:40 IST the ceilometer detects clouds at $0.786 \mathrm{~km}$ and MODIS at $11.25 \mathrm{~km}$. This indicates that MODIS provides the information about high- level cirrus clouds and the ceilometer provides the information about low-level clouds. Figure $5 \mathrm{~b}$ shows that cloud moved with almost constant velocity from 14:20 to 14:30 IST on 25 July 2014 and the CBH detected by the ceilometer is $1.92 \mathrm{~km}$. The CTH from the MODIS satellite is $4.25 \mathrm{~km}$ which shows the mid-level clouds and by applying the algorithm, the CBH is calculated as $2.2 \mathrm{~km}$. So, the difference between the base height measured by the ceilometer and by MODIS is $\sim 130 \mathrm{~m}$. Multilayer clouds appear in Fig. $5 \mathrm{c}$ measured by the ceilometer from 02:00 to 04:00 IST. It shows the beauty of this instrument to detect the three layers of clouds, and MODIS provides CTH at $3.4 \mathrm{~km}$. Here, the CBH algorithm for the MODIS satellite is not applicable due to the non-availability of cloud optical thickness and effective radius. Figure 5d shows that on 1 January 2015 from 14:00 to 16:00 IST, multilayered clouds appeared at a height of around $1 \mathrm{~km}$ and the second layer appeared at around $1.5 \mathrm{~km}$ for the first $15 \mathrm{~min}$. The continuous updraft of cloud from 1 to $2 \mathrm{~km}$ till 16:00 IST was observed. At a common point (at 14:25 IST), the CBH by the ceilometer is $1.097 \mathrm{~km}$ and CTH provided by MODIS is $2 \mathrm{~m}$, and from the algorithm, CBH is calculated as $1.093 \mathrm{~km}$, which is almost the same as the CBH measured by the ceilometer. Therefore, it can be concluded that for low-level clouds, this algorithm is fine. The cloud cover for monsoon and post-monsoon periods during the year 2014 was also studied, and the variation of CBH with rain and without rain was found.

\subsection{Cloud characteristics during monsoon}

- Rainy clouds:

on 5 September 2014 from 11:00 to 12:00 IST, the ceilometer detected low-level clouds which move with almost constant velocity. At 11:55 IST, the ceilometer detects the $\mathrm{CBH}$ at $0.82 \mathrm{~km}$, which shows the availability of low-level clouds, and MODIS detected CTH as 

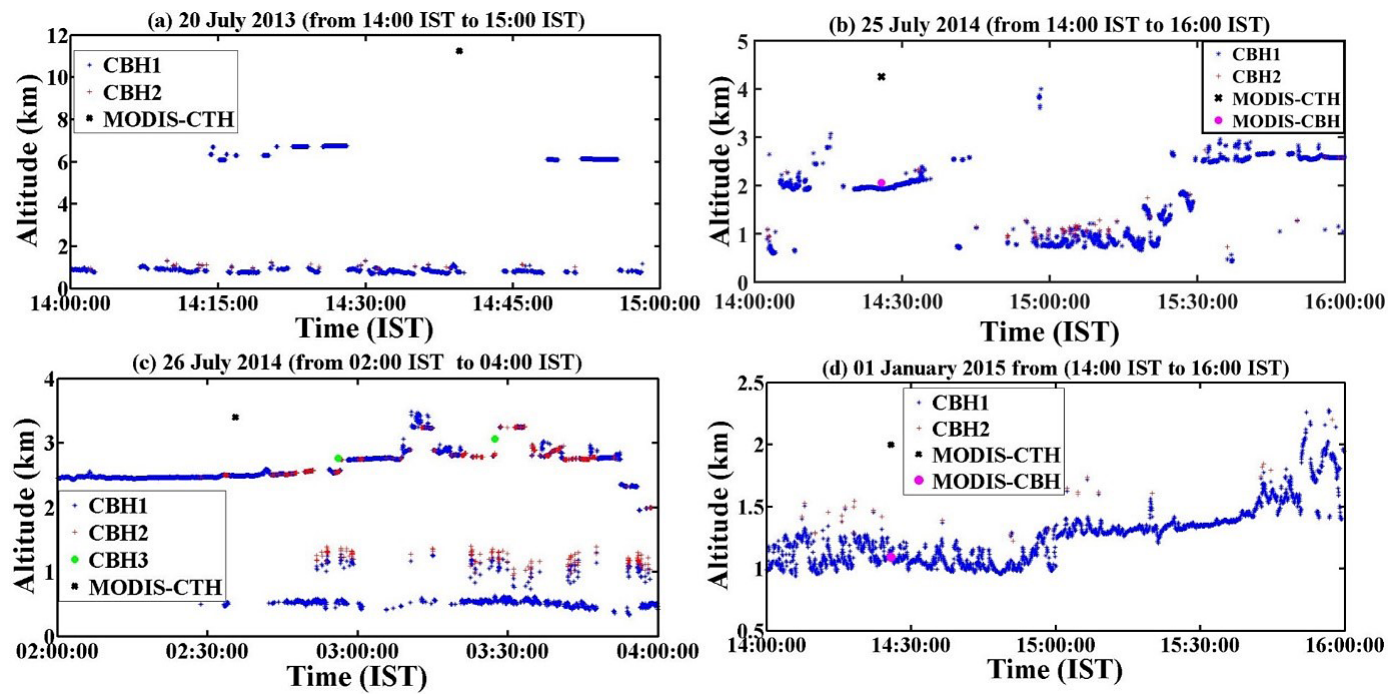

Figure 5. Comparison between cloud top height and CBH derived from MODIS, and base height measured by Ceilometer CL31 over the Ahmedabad region.

$4.25 \mathrm{~km}$, which provides information about mid-level clouds. On that day, rainfall amount was reported as $21 \mathrm{~mm}$, shown in Fig. 6a.

- Heavy rain:

on 30 July 2014, low-level clouds were detected which move with almost constant velocity. At 11:35 IST, CBH measured by the ceilometer is $0.4 \mathrm{~km}$ and $\mathrm{CTH}$ retrieved by MODIS is $10.9 \mathrm{~km}$, which provides information on high-level clouds. On that day, rainfall amount was $207 \mathrm{~mm}$ which is the maximum, as shown in Fig. 6 b.

- Non-rainy clouds:

on 15 September 2014 from 10:00 to 11:00 IST, cloud over the Ahmedabad region detected by the ceilometer is shown in Fig. 6c. It detects the $\mathrm{CBH}$ at $0.9 \mathrm{~km}$, which provides information on low-level clouds, and the CTH retrieved from the MODIS satellite is $1.25 \mathrm{~km}$.

\subsection{Cloud characteristics during post-monsoon}

- Rainy clouds:

on 15 November 2014 strong updraft and downdraft were observed. Clouds moved downward at a velocity of $14.79 \mathrm{~m} \mathrm{~s}^{-1}$ from $16: 51$ to $16: 56$ IST and moved upward at a velocity of $15.13 \mathrm{~m} \mathrm{~s}^{-1}$ from 17:08 to 17:15 IST, as shown in Fig. 7a.

- Non-rainy clouds:

Fig. 7b shows that on 30 October 2014 from 02:00 to 03:00 IST high-level clouds are detected by the ceilometer over the Ahmedabad region. Between 02:26 and 02:41 IST, the ceilometer shows clear sky, and the CTH

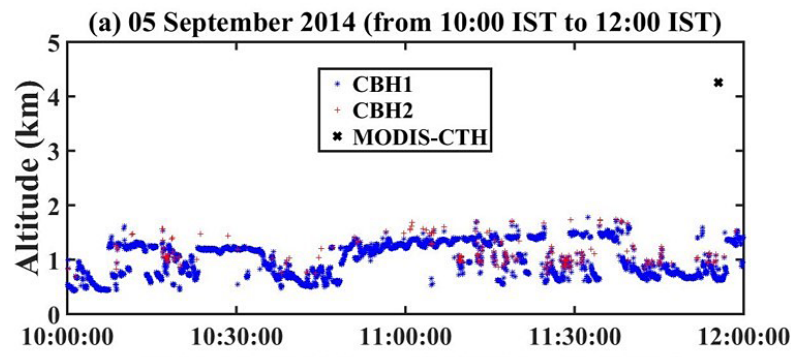

(b) 30 July 2014 (from 10:00 IST to 12:00 IST)
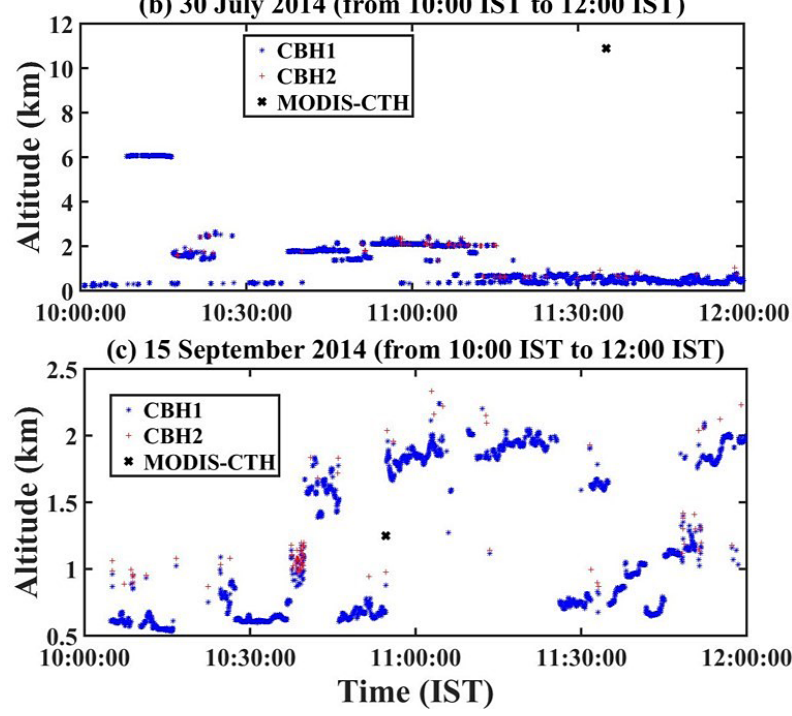

Figure 6. Comparison between cloud top height derived from MODIS, and $\mathrm{CBH}$ observed by the ceilometer during the monsoon season over the Ahmedabad region during sample days for (a) normal rain, (b) heavy rain, and (c) no rain cases. 
(a) 15 November 2014 (from 12:00 IST to 00:00 IST)

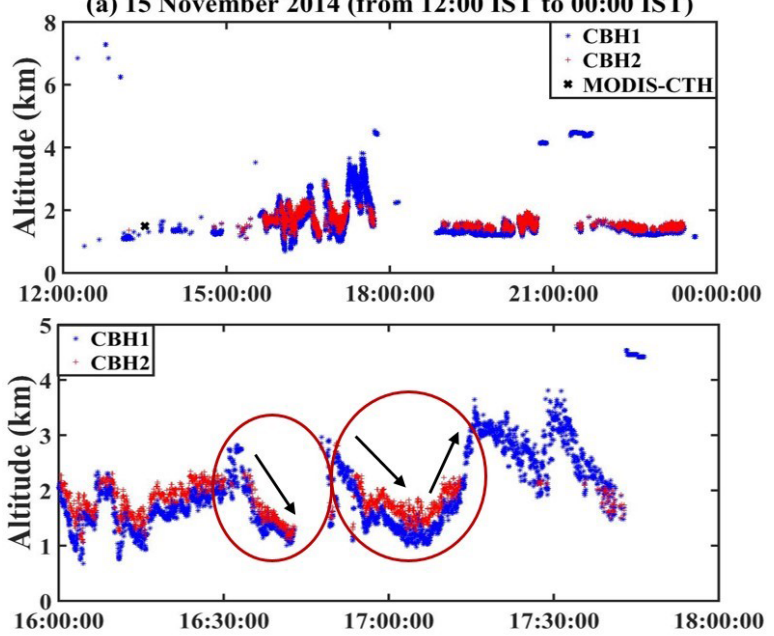

(b) 30 October 2014 (from 02:00 IST to 04:00 IST)

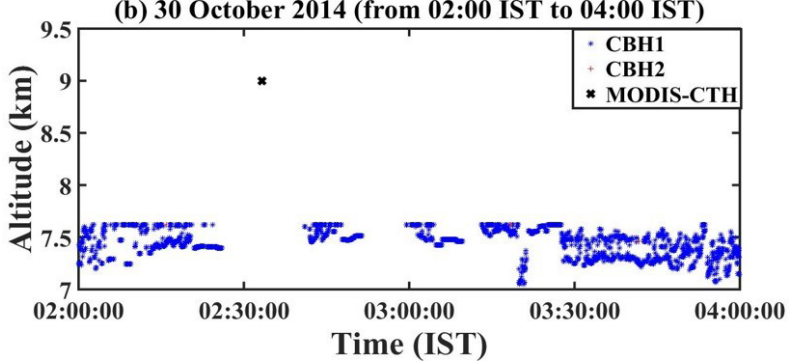

Figure 7. Comparison between cloud top height derived from MODIS, and CBH observed by the ceilometer during the monsoon season over the Ahmedabad region during sample days for (a) rain, and (b) no rain cases.

detected by MODIS is $9 \mathrm{~km}$. Higher level clouds are much better detected in the satellite data than by the ceilometer due to a power limitation; therefore, the ceilometer can detect a maximum up to $7.5 \mathrm{~km}$.

\section{Conclusions}

For the first time, cloud characteristics have been produced over Ahmedabad for the total cloudiness as a physical parameter, using observations from Ceilometer CL31 and the MODIS satellite. The study of cloud types and cloud cover fraction (total cloudiness) at Ahmedabad during May 2013January 2015 has shown the following findings. (1) Some strong downdraft and updraft were found. Clouds moved downward at a velocity of $14.8 \mathrm{~m} \mathrm{~s}^{-1}$ and upward at a velocity of $15.1 \mathrm{~m} \mathrm{~s}^{-1}$ on 15 November 2014. (2) CBH shows variations during the southwest monsoon and the post-monsoon period. (3) The ground-measured cloudiness due to low-level and mid-level clouds is obviously higher than the one determined by the satellite. Overall, the ceilometer provides information on up to three layers of clouds, which are not possible to detect by the MODIS satellite. The satellite only provides the $\mathrm{CTH}$; moreover, the satellite gives information about cloud height twice in a day when it passes over the Ahmedabad region, but the ceilometer provides regular (high temporal frequency) and real-time information. The low-level clouds are not accurately detected by the satellite as shown in the observation table, whereas the satellite provides information about high-level clouds. The high-level clouds are accurately captured by satellite data compared to ceilometer measurements due to the power limitation of the ceilometer; because of that it can measure up to $7.5 \mathrm{~km}$. The comparison of the cloud cover from satellite observations with that of the ground-based observations suggests that the low- and midlevel clouds are much better and accurately detected by the Ceilometer CL31 ground-based instrument than the satellite, and the satellite provides better information about high-level clouds. Also, it is important to note here that the $\mathrm{CBH}$ algorithm is valid for low-level clouds but mostly fails due to the absence of cloud optical thickness and effective radius. Finally, the cloud detection can be obtained by the combination of ground-based observations and satellite observations, which can be used for further weather modeling purposes which need accurate cloud information to initialize numerical models.

Acknowledgements. Authors are thankful to the Indian Space Research Organization (ISRO) Geosphere-Biosphere Program (GBP) for financial support for instruments. Authors are also grateful to NASA for MODIS-retrieved products; these satellite data are available from http://ladsweb.nascom.nasa.gov/ and http://modis.gsfc.nasa.gov/. This work is supported by PRL, Department of Space, government of India. The Indian Meteorological Department is acknowledged for rainfall reports over India.

Edited by: A. Kokhanovsky

\section{References}

Albrecht, B. A., Fairall, C. W., Thomson, D. W., White, A. B. Snider, J. B., and Schubert, W. H.: Surface-based remote sensing of the observed and the adiabatic liquid water content of stratocumulus clouds, Geophys. Res. Lett., 17, 89-92, 1990.

Andrejczuk, M., Gadian, A., and Blyth, A.: Numerical simulations of stratocumulus cloud response to aerosol perturbation, Atmos. Res., 140, 76-84, 2014.

Bauer, P., Auligné, T., Bell, W., Geer, A., Guidard, V., Heilliette, S., Kazumori, M., Kim, M.J., Liu, E. H. C., McNally, A. P., and Macpherson, B.: Satellite cloud and precipitation assimilation at operational NWP centres, Q. J. Roy. Meteor. Soc., 137, 1934 1951, 2011.

Bhat, G. S. and Kumar, S.: Vertical structure of cumulonimbus towers and intense convective clouds over the South Asian region during the summer monsoon season, J. Geophys. Res.-Atmos., 120, 1710-1722, 2015.

Clothiaux, E. E., Ackerman, T. P., Mace, G. G., Moran, K. P., Marchand, R. T., Miller, M. A., and Martner, B. E.: Objective deter- 
mination of cloud heights and radar reflectivities using a combination of active remote sensors at the ARM CART sites, J. Appl. Meteorol., 39, 645-665, 2000.

Costa-Surós, M., Calbó, J., González, J. A., and Martin-Vide, J.: Behavior of cloud base height from ceilometer measurements, Atmos. Res., 127, 64-76, 2013.

Duynkerke, P. G. and Teixeira, J.: Comparison of the ECMWF reanalysis with FIRE I observations: Diurnal variation of marine stratocumulus, J. Climate, 14, 1466-1478, 2001.

Errico, R. M., Bauer, P., and Mahfouf, J. F.: Issues regarding the assimilation of cloud and precipitation data, J. Atmos. Sci., 64, 3785-3798, 2007.

Fontana, F., Lugrin, D., Seiz, G., Meier, M., and Foppa, N.: Intercomparison of satellite-and ground-based cloud fraction over Switzerland (2000-2012), Atmos. Res., 128, 1-12, 2013.

Forsythe, J. M., Vonder Haar, T. H., and Reinke, D. L.: Cloud-base height estimates using a combination of meteorological satellite imagery and surface reports, J. Appl. Meteorol., 39, 2336-2347, 2000.

Gu, L., Ren, R., and Zhang, S.: Automatic cloud detection and removal algorithm for MODIS remote sensing imagery, Journal of Software, 6, 1289-1296, 2011.

Hess, M., Koepke, P., and Schult, I.: Optical properties of aerosols and clouds: The software package OPAC, B. Am. Meteorol. Soc., 79, 831-844, 1998.

Hirsch, E., Agassi, E., and Koren, I.: A novel technique for extracting clouds base height using ground based imaging, Atmos. Meas. Tech., 4, 117-130, doi:10.5194/amt-4-117-2011, 2011.

Hutchison, K. D.: The retrieval of cloud base heights from MODIS and three-dimensional cloud fields from NASA's EOS Aqua mission, Int. J. Remote Sens., 23, 5249-5265, 2002.

Hutchison, K., Wong, E., and Ou, S. C.: Cloud base heights retrieved during night-time conditions with MODIS data, Int. J. Remote Sens., 27, 2847-2862, 2006.

Kassianov, E., Long, C. N., and Christy, J.: Cloud-base-height estimation from paired ground-based hemispherical observations, J. Appl. Meteorol., 44, 1221-1233, 2005.

Kiehl, J. T. and Trenberth, K. E.: Earth's annual global mean energy budget, B. Am. Meteorol. Soc., 78, 197-208, 1997.

Kim, S. W., Chung, E. S., Yoon, S. C., Sohn, B. J., and Sugimoto, N.: Intercomparisons of cloud-top and cloud-base heights from ground-based Lidar, CloudSat and CALIPSO measurements, Int. J. Remote Sens., 32, 1179-1197, 2011.

Kokhanovsky, A. A., Vountas, M., Rozanov, V. V., Lotz, W., Bovensmann, H., and Burrows, J. P.: Global cloud top height and thermodynamic phase distributions as obtained by SCIAMACHY on ENVISAT, Int. J. Remote Sens., 28, 4499-4507, 2007.

Koren, I., Remer, L. A., Altaratz, O., Martins, J. V., and Davidi, A.: Aerosol-induced changes of convective cloud anvils produce strong climate warming, Atmos. Chem. Phys., 10, 5001-5010, doi:10.5194/acp-10-5001-2010, 2010.

Kotarba, A. Z.: A comparison of MODIS-derived cloud amount with visual surface observations, Atmos. Res., 92, 522-530, 2009.

Li, R. and Min, Q.-L.: Impacts of mineral dust on the vertical structure of precipitation, J. Geophys. Res., 115, D09203, doi:10.1029/2009JD11925, 2010.
Liu, L., Sun, X. J., Liu, X. C., Gao, T. C., and Zhao, S. J.: Comparison of Cloud Base Height Derived from a Ground-Based Infrared Cloud Measurement and Two Ceilometer, Advances in Meteorology, 2015, 853861, doi:10.1155/2015/853861, 2015.

Martucci, G., Matthey, R., Mitev, V., and Richner, H.: Comparison between backscatter lidar and radiosonde measurements of the diurnal and nocturnal stratification in the lower troposphere, J. Atmos. Ocean Tech., 24, 1231-1244, 2007.

Martucci, G., Milroy, C., and O'Dowd, C. D.: Detection of cloudbase height using Jenoptik CHM15K and Vaisala CL31 ceilometer, J. Atmos. Ocean Tech., 27, 305-318, 2010.

Meerkötter, R. and Zinner, T.: Satellite remote sensing of cloud base height for convective cloud fields: A case study, Geophys. Res. Lett., 34, L17805, doi:10.1029/2007GL030347, 2007.

Meerkötter, R. and Bugliaro, L.: Diurnal evolution of cloud base heights in convective cloud fields from MSG/SEVIRI data, Atmos. Chem. Phys., 9, 1767-1778, doi:10.5194/acp-9-1767-2009, 2009.

Naud, C., Muller, J.-P., and Clothiaux, E. E.: Comparison between active sensor and radiosonde cloud boundaries over the ARM Southern Great Plains site, J. Geophys. Res., 108, 4140, doi:10.1029/2002JD002887, 2003.

Norris, J. R.: Low cloud type over the ocean from surface observations. PART II: Geographical and and seasonal variations, J. Climate, 11, 383-403, 1998.

Pal, S. R., Steinbrecht, W., and Carswell, A. I.: Automated method for lidar determination of cloud-base height and vertical extent, Appl. Optics, 31, 1488-1494, 1992.

Randall, D. A.: Stratocumulus cloud deepening through entrainment, Tellus A, 36, 446-457, 1984.

Rasmusen, R. M., Geresdi, I., Thompson, G., Manning, K., and Karplus, E.: Freezing drizzle formation in stably stratified layer clouds: The role of radiative cooling of cloud droplets, cloud condensation nuclei, and ice initiation, J. Atmos. Sci., 59, 837-860, 2002.

Rosenfeld, D. and Lensky, I. M.: Satellite-based insights into precipitation formation processes in continental and maritime convective clouds, B. Am. Meteorol. Soc., 79, 2457-2476, 1998.

Shah, S., Rao, B.M., Kumar, P., and Pal, P. K.: Verification of cloud cover forecast with INSAT observation over western India, J. Earth Syst. Sci., 119, 775-781, 2010.

Stefan, S., Ungureanu, I., and Grigoras, C.: A survey of cloud cover over Magurele, Romania, using ceilometer and satellite data, Rom. Rep. Phys., 66, 812-822, 2014.

Varikoden, H., Harikumar, R., Vishnu, R., Sasi Kumar, V., Sampath, S., Murali Das, S., and Mohan Kumar, G.: Observational study of cloud base height and its frequency over a tropical station, Thiruvananthapuram, using a ceilometer, Int. J. Remote Sens., 32, 8505-8518, 2011.

Weisz, E., Li, J., Menzel, W. P., Heidinger, A. K., Kahn, B. H., and Liu, C. Y.: Comparison of AIRS, MODIS, CloudSat and CALIPSO cloud top height retrievals, Geophys. Res. Lett., 34, L17811, doi:10.1029/2007GL030676, 2007.

Winker, D. M., Pelon, J. R., and McCormick, M. P.: The CALIPSO mission: Spaceborne lidar for observation of aerosols and clouds, Proc. SPIE Int. Soc. Opt. Eng., 4893, 1-11, 2003.

Wu, L., Su, H. and J. H., Jiang H. J.: Regional simulations of deep convection and biomass burning over South America: 2. Biomass 
burning aerosol effects on clouds and precipitation, J. Geophys. Res., 116, D17209, doi:10.1029/2011JD016106, 2011.

Xiong, X., Chiang, K. F., Sun, J., Che, N., and Barnes, W. L.: Aqua MODIS first year on-orbit calibration and performance, Proceedings of SPIE - Sensors, Systems, and Next Generation of Satellites VII, 5234, 391-399, doi:10.1117/12.510580, 2004.
Zhang, J., Chen, H., Li, Z., Fan, X., Peng, L., Yu, Y., and Cribb, M. Analysis of cloud layer structure in Shouxian, China, using RS92 radiosonde aided by $95 \mathrm{GHz}$ cloud radar, J. Geophys. Res., 115, D00K30, doi:10.1029/2010JD014030, 2010. 